\title{
Study on interventions to reduce vibration transmission to power tiller operator
}

\author{
Varun Chaturvedi", Adarsh Kumar, I. M. Mishra, J. K. Singh, R. N. Sahoo, G. K. Jha and \\ S. B. Lal
}

Department of Agricultural Engineering, IARI, PUSA Campus, New Delhi-110012, INDIA

Corresponding author. E-mail: varun30246@gmail.com

Received: June 10, 2015; Revised received: October 30, 2015; Accepted: February 23, 2016

\begin{abstract}
Present study focuses on interventions to reduce vibration transmitted to power tiller operator. In this study two operations (namely: standing mode and transportation) and three forward speeds $\left(1.0,1.5 \mathrm{and}^{\left.2.0 \mathrm{kmh}^{-1}\right)}\right.$ were selected. In both selected operations vibration magnitudes were maximum at $2.0 \mathrm{kmh}^{-1}$. In the standing mode vibration magnitudes in $\mathrm{x}, \mathrm{y}$ and $\mathrm{z}$ direction were $5.83,1.37$ and $2.36 \mathrm{~ms}^{-2}$ at $2.0 \mathrm{kmh}^{-1}$. In transportation vibration magnitudes were $6.81,1.49,2.82 \mathrm{~ms}^{-2}$ respectively in $\mathrm{x}, \mathrm{y}$ and $\mathrm{z}$ direction at $2.0 \mathrm{kmh}^{-1}$. The selection of vibration isolators were done on the basis of the transmissibility curves and the isolation region. The selected isolators were installed at interface between engine and the chassis. These interventions along with previously developed bush and sheet type interventions reduced vibrations up to 50.24, 69.06 and $59.08 \%$ at $1.0,1.5$ and $2.0 \mathrm{kmh}^{-1}$ in stationary mode. In transportation vibration reduction were 52.96, 65.98 and $36.67 \%$ at 1.0, 1.5 and $2.0 \mathrm{kmh}^{-1}$, respectively. The vibration reduction were high in stationary mode than transportation mode because in stationary mode vibration comes only from the engine but in transportation vibration comes from engine and the surface profile as well.
\end{abstract}

Keywords: Hand-arm vibration, Interface, Isolation region, Transmissibility curves, Vibration isolator

\section{INTRODUCTION}

In India, power tiller is used at the countryside both for tillage and transportation. The average size of holding for all operational classes (small and marginal, medium and large) have declined over the years and has come down to 1.16 hectare in 2010-11 from 2.82 hectare in 1970-71 (Anonymous, 2013). The presence of a large number of small holdings has rendered the power tiller to be most suitable farm power source in view of its compact size, versatility and cost. The current market of power tiller in India is estimated as 56000 numbers during 2013-14 (Mehta et al., 2014).

In power tiller operation, one of the major safety concern has been the exposure to a high intensity vibrations at interface of hand and handle. Hand-transmitted vibration of a power tiller is very severe as handle grip is a cantilever beam, and power is obtained from a single cylinder diesel engine (Ying et al., 1998). The detrimental effect of the prolonged exposure to hand-arm vibration on the operators have been known for a long time and occupational health disorders are referred to as vibration induced white fingers (VWF) or hand-arm vibration syndrome (HAVS).

Many studies have been done on tractors but very few studies have been conducted on power tillers. Researchers had quantified the exposure in power tiller operation. Mehta et al. (1997) studied the vibrations on a $7.5 \mathrm{~kW}$ rotary power tiller. They concluded that acceleration levels varied widely and were greatly dependent on variables such as forward speed, terrain and mode of operation. Ragni et al. (1993) reported that if hand tractors are used at least for $4 \mathrm{~h}$ per day, the time expected for the appearance of the disorders was 3 years, for $10 \%$ of the operators.

Tewari et al. (2004) studied the operators fatigue in field operation of hand tractors. In this study a hand tractor was modified to enable operation in a seated position. The vibration intensity (rms acceleration) was observed to be as high as $45 \mathrm{~ms}^{-2}$ without the seat whereas this value was $20 \mathrm{~ms}^{-2}$ with the seating arrangement. Binisam and Kathirvel (2006) studied the characteristics of both walking and riding type power tillers. They concluded that hand arm system was most sensitive in the frequency range of $6.3-16 \mathrm{~Hz}$ and a seated man was most sensitive in the frequency range of 4-8 Hz. The walking type power tiller showed higher hand transmitted vibration (HTV) than riding type during rota-tilling, whereas riding type power tiller exhibited higher hand transmitted and whole body vibrations during transport mode. There are very few studies which have focused on intervention development to reduce vibrations. The interventions used are of three types namely, at handle as handle grip, between handle and chassis and between chassis and the engine. Researchers had made provision for seat to make the operator comfortable and reduce hand arm vibrations, but at the cost of inducing whole body vibrations. Binisam 
and Kathirvel (2009) developed the vibration isolators for engine, handle bar and the handle. Combined effect of three stages of reduction in vibration was measured and analyzed to know the reduction of machine vibration in walking and riding type power tillers in stationary condition. The results indicated that provision of vibration isolators reduced handle vibration by 50-60\%. The critical point was that these interventions are of invasive type. In these type the handle was cut to install the intervention. Dewangan and Tewari (2010) developed two different designs of handle grips made of foam rubber and the styrene-butadiene rubber (SBR). The results indicated that the handle grip made of foam rubber and SBR could reduce frequency weighted vibration acceleration (rms) by about $11 \%$ and $5 \%$, respectively.

Chaturvedi et al. (2012) developed bush and sheet types interventions to reduce the vibration in power tiller without disturbing the structure of the machine. The material used for these interventions were commercially available rubber and polyurethane (PU). The maximum reduction of $25.30 \%, 31.21 \%$ and $30.45 \%$ with PU, rubber and combination of PU and rubber was achieved at $1.5 \mathrm{kmh}^{-1}$ speed in the vibration magnitudes. The experiment showed that PU interventions were sustainable for longer time because of its strength. In power tiller, three types of interfaces exist. First is between hand and handle bar of power tiller, second is between handle bar and the chassis and the third is between engine and the chassis. The vibration transmission to operator can be reduced with the application of the interventions on these interfaces. In the present study two modes (standing and the transportation) were selected. In both the modes the single cylinder engine of the power tiller is the main contributor of the hand arm vibration. So the interface between engine and the chassis play a big role to isolate the engine vibration. Keeping in view all the above research works in the present study, the hand arm vibration were measured in stationary and the transportation mode. Selection of interventions were done to reduce the engine vibration transmitted to the power tiller operator. High intensity of vibration exposure in the power tiller operation is the main cause of the ill effect i.e. HAVS. In this study the vibration reduction were determined with the application of the selected interventions.

\section{MATERIALS AND METHODS}

Design and fabrication of experimental set-up and selection of operational conditions for measurement of vibration magnitudes

Theoretical consideration: Exposure of the human to hand-arm vibration (hand-transmitted vibration) is very complex. Vibration occurs in three translational axes. The vibration frequencies may extend over a wide range. The vibration received by an operator depends on his technique and varies according to the dynamic response of his finger, hands and arms. While recognizing the complexity of vibration exposures to the hand, it is essential to define a simple means of quantifying the vibration (Griffin, 1996).

Direction of vibration: It is known that the vibration entering the hand contains contributions from all threemeasurement directions. Therefore the measurement should preferably be made for all three directions simultaneously. Fig. 1 illustrates an anatomical and basicentric coordinate system for measurement of handarm vibration exposure as defined in ISO 5349 (2001). In practice, measurements are usually obtained with respect to a basicentric coordinate system centered on (or adjacent to) the vibrating surface (Griffin, 1996). The z-axis, is defined as the longitudinal axis of the third metacarpal bone and is oriented positively towards the distal end of the finger. The $\mathrm{x}$-axis passes through the origin, is perpendicular to the z-axis, and is positive in the forward direction when the hand is in the normal anatomical position (palm facing forwards). The $y$-axis is perpendicular to the other two axes and is positive in the direction towards the fifth finger (thumb). The system is generally rotated in the $y-z$ plane so that the y-axis is parallel to the handle axis.

Magnitude of vibration: Mechanical vibrations in a machine are caused by the moving components of the machine. Since a machine may consist of many such moving components, the overall vibrations transmitted to the human body in contact with the machine are made up of vibrations of different frequencies occurring simultaneously. Human response to vibration is highly dependent on the frequency of the vibration. In the ISO 5349 (2001) recommendations, the most important quantity used to describe the magnitude of vibration transmitted to the operator's hands is root mean square (rms) frequency-weighted acceleration in $\mathrm{ms}^{-2}$ expressed as

$$
a_{h w}=\left[\sum_{j=1}^{n}\left(W_{h} a_{h j}\right)^{2}\right]^{1 / 2}
$$

\section{Where}

$\mathrm{a}_{\mathrm{hw}}$ - root mean square (rms) frequency weighted acceleration

$\mathrm{W}_{\mathrm{h}}$ - weighting factor for the $\mathrm{j}^{\text {th }}$ one-third-octave

$\mathrm{a}_{\mathrm{hj}}$ - rms acceleration measured in one-third-octave bands used in $\mathrm{ms}^{-2}$

$n$ - number of frequencies used in the octave band

The weighted value should be determined over the eight octave bands (i.e., $\mathrm{n}=8$ ) from 8 to $1000 \mathrm{~Hz}$ or over the 24 one third octave bands (i.e., $n=24$ ) from 6.3 to $1250 \mathrm{~Hz}$. The one-third octave band is very common and is adopted in the ISO 5349 (2001). The sensitivity of body to different frequencies are different, so weighting factor for different frequency bands are defined in ISO 5349 (2001).

The evaluation of vibration exposure in accordance with ISO 5349 (2001) is based on a quantity that combines all three axes. This is the vibration total value $a_{h v}$ 
(vector sum) and it is defined as the rms of the three component values

$$
a_{h v}=\sqrt{\left(a_{h w x}\right)^{2}+\left(a_{h w y}\right)^{2}+\left(a_{h w z}\right)^{2}}
$$

Where

$\mathrm{a}_{\mathrm{hv}}$ - total $\mathrm{rms}$ acceleration at the handle in $\mathrm{ms}^{-2}$

$a_{h w x}-r m s$ acceleration in the $x$-axis in $\mathrm{ms}^{-2}$

$a_{\text {hwy }}$ - rms acceleration in the $y$-axis in $\mathrm{ms}^{-2}$

$a_{\text {hwz }}-r m s$ acceleration in the $\mathrm{z}$-axis in $\mathrm{ms}^{-2}$

Therefore the vector sum of vibration intensity is virtually independent of the orientation of the coordinate system.

Tasks : To assess vibration two operational conditions were considered, namely stationary mode and transportation on farm road. The power tiller was operated at three different engine speeds in the stationary mode and three different forward speeds (1.0, 1.5 and 2.0 $\mathrm{kmh}^{-1}$ ) during transportation. All the three speeds were achieved in second gear position and at the different accelerator lever positions.

\section{Equipment and procedure}

Power tiller: A 13 HP VST Shakti 130 DI, type power tiller manufactured in India and commonly used by the farmers was selected for the study. The power tiller was powered with a single cylinder, four stroke, water cooled and horizontal diesel engine of $130 \mathrm{~kg}$ weight. The power of engine was transmitted to the transmission box with the help of three v-belts and pulleys. From the transmission box power was transmitted to the ground wheels and the rotating element. Two clutches on the handle facilitated turning of power tiller. One main clutch had a provision to stops the power from transmission box to ground wheels and the rotating element.

The power tiller had provision for two attachments namely rotavator and cultivator. The rotavator attachment had a $600 \mathrm{~mm}$ wide rotating element with 18 tyne blades fitted on the shaft of the rotor. The cultivator had a width of $570 \mathrm{~mm}$ with 5 numbers of tynes with reversible shovel.

Adapter: An adapter was used for attachment of transducer to measure the vibration intensity of hand-arm system. The adapter was made up of the aluminum alloy .A lightweight tri-axial accelerometer was fixed by a stud in the adapter to measure vibration acceleration. The design of the adapter was such that the accelerometer should lie in between the index and middle finger. The total weight of the adapter including the accelerometer was $22.5 \mathrm{~g}$.

The adapter was mounted according to the ISO 5349 (2001) on the handle bar of the tractor with the help of the metal straps. After mounting, the adapter should act as a integral part of the power tiller, so that it can sense the actual vibration levels as of the handle of the power tiller and there should not be any vibration dampening in between the adapter and the handle. The adapter was mounted on the right hand handle bar of the power tiller.

Tri-axial accelerometer: To measure the vibration magnitude one tri-axial accelerometer (PCB piezotronics) was used. The accelerometer was mounted on the adapter with the help of a stud (Fig. 2). The position of hand on the handle bar (Fig. 2a) was such that it followed the directions according to the ISO standard.

Data acquisition system: A portable digital, sound and vibration meter and analyzer (AIDA Vibra., Italy) was used for data acquisition (Fig. 2(b)). It has four channel architecture and integrates mass storage recording capability. Vibration analyzing fulfils requirements according to ISO 5349 (2001) and ISO 2631-1 (1997). Sound analysis fulfils class I requirements according to IEC 61672 and IEC 61260 standards.

BNC and LEMO port consists four acquisition channels allow simultaneously performing both vibration and sounding measurement with $24 \mathrm{bit}, 48 \mathrm{kHz}$ converters, being able to monitor and record signals with band from $22 \mathrm{kHz}$ to $0.01 \mathrm{~Hz}$. It has a lowconsumption processor with great compatibilities, ensuring real time analysis such as $1 / 3$ octave real time analysis (according to IEC 61260) on the whole band $0.63 \mathrm{~Hz}$ to $22 \mathrm{kHz}$ for every acquisition channel. The acquisition system has $56.2 \mathrm{~ms}^{-2}$ and $1000 \mathrm{~ms}^{-2}$ two measuring ranges. A four-pin cable makes a connection between the accelerometer and the data analyzing system. The signal was pre-amplified before recording by a four channel data-acquisition system. The data stored in the data-acquisition system was downloaded on a personal computer at the end of the experiment for further analysis.

Assessment of vibration magnitudes during different selected operational conditions: The vibration measurements and analysis were carried out as outlined in the Fig. 3. The handle adapter was rigidly fixed on the right side of the power tiller by metal straps. The accelerometer was mounted on the adapter with the help of a stud to measure the vibration intensity at the handle. The handle adapter was fixed such that the inclination of the metacarpus bone, when the hand grasped the grip, was at $45^{\circ}$ to the vertical. The accelerometer mounted on the adapter was tightly secured to avoid any relative motion between the measuring point and the accelerometer.

Development of interventions to reduce the magnitudes of vibration: In the previous study (Chaturvedi et al., 2012) the bush and the sheet type interventions were developed for the interface between handle and the chassis. Polyurethane, rubber and combination of PU and rubber were used for the interventions. The results shows the life cycle of the interventions developed by the polyurethane were highest among all. So on the basis of the results the previously developed polyurethane interventions were further used. 
The main source of the vibrations in power tiller was unbalanced single cylinder horizontal engine. So in the present study interventions were selected for the interface between engine and the chassis. The selection of the isolators was done on the basis of the region of amplification, region of isolation and isolation efficiency. Referring to Fig. 4a (Rao, 2000), it can be seen that when the ratio of the disturbing frequency $f_{d}$ over the natural frequency $f_{n}$ is less than or 1.4 , the transmissibility is greater than 1 , or the equipment experiences amplification of the input. Simply expressed, when:

$$
f d / f n \leq \sqrt{2}, \quad T \geq 1
$$

theoretically, isolation begins when:

$$
f d / f n=\sqrt{2} \text {, at this point } T=1
$$

Also it can be seen that when:

$$
f d / f n \succ-T \prec
$$

the mounted unit is said to be isolated.

The relationship between a highly damped and a lightly damped system is illustrated in Fig. 4b (Rao,
2000). Figure $4 \mathrm{~b}$ shows that as damping increases, isolation efficiency reduces in the isolation region. While high values of damping cause significant reduction of transmissibility at resonance, its effect in the isolation region is only a small increase in transmissibility.

The selected interventions (Fig. 6) were integrated with previously developed interventions (Fig. 5) and experiments were conducted to assess vibration reduction.. The dimensions of selected interventions were given in the Table 1.

\section{RESULTS AND DISCUSSION}

Vibration magnitudes of power tiller without interventions: The vibration magnitudes in stationary mode increased with increase in the speed without interventions. The vibration magnitudes in the $\mathrm{x}$ direction were $5.74,5.12$ and $5.83 \mathrm{~ms}^{-2}$ at $1.0,1.5$ and $2.0 \mathrm{kmh}^{-1}$. The magnitudes were 1.16. 1.28 and $1.37 \mathrm{~ms}^{-2}$ in y direction at selected speeds. In $\mathrm{z}$ direction magnitudes were 1.87, 1.93 and $2.36 \mathrm{~ms}^{-2}$ at $1.0,1.5$ and $2.0 \mathrm{kmh}^{-1}$. These vibration magnitudes are shown in the Fig. 7.

The vibration magnitudes in transportation mode are shown in the Fig. 8.

In transportation mode vibration magnitudes were
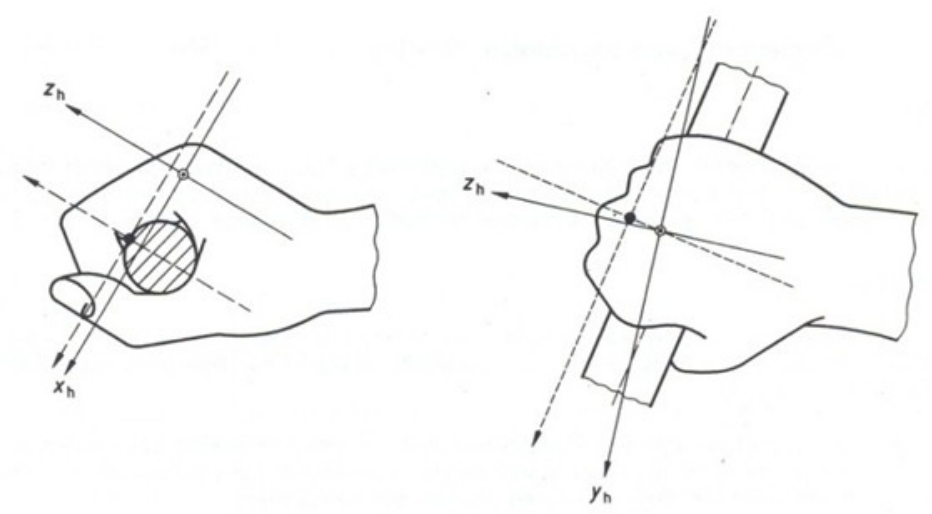

-------Basicentric coordinate system, Biodynamic coordinate system Fig. 1. Coordinate system for the hand.
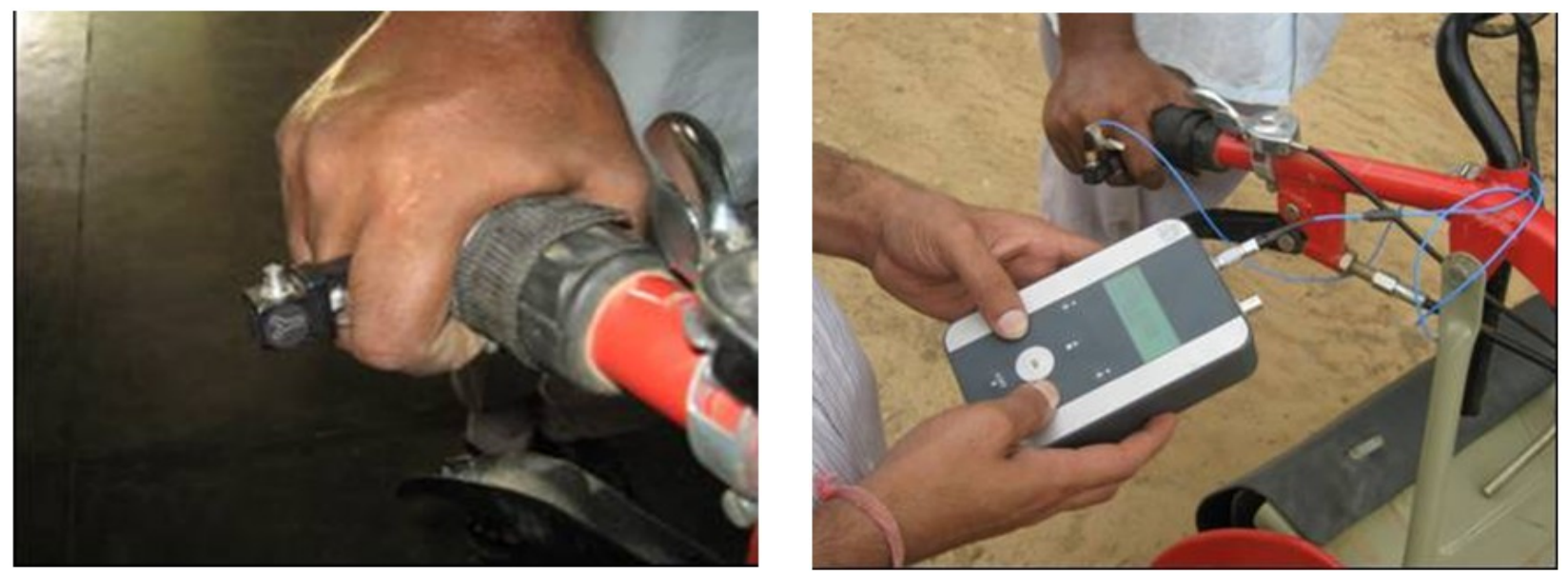

Fig. 2. (a) Triaxial Accelerometer mounted on an adopter (b) Data acquisition system. 


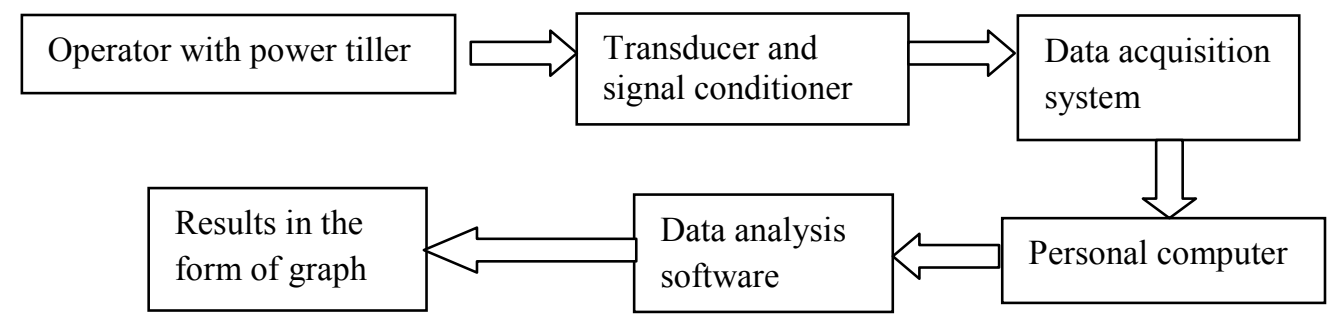

Fig. 3. Schematic diagram of the experimental set-up for measuring vibration acceleration in the hand-arm system
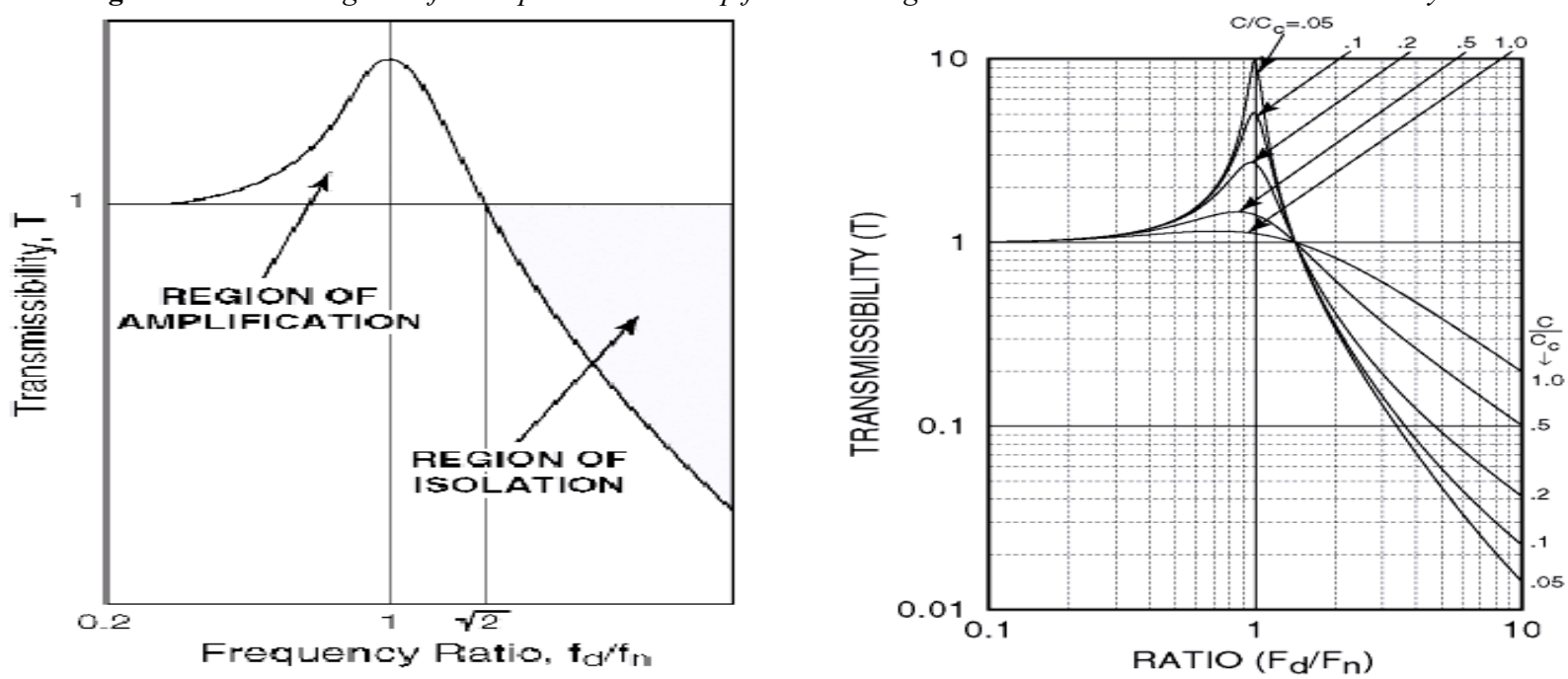

Fig. 4. (a) Typical transmissibility curve for an isolated system (b) Family of transmissibility curves for a single degree of freedom system.
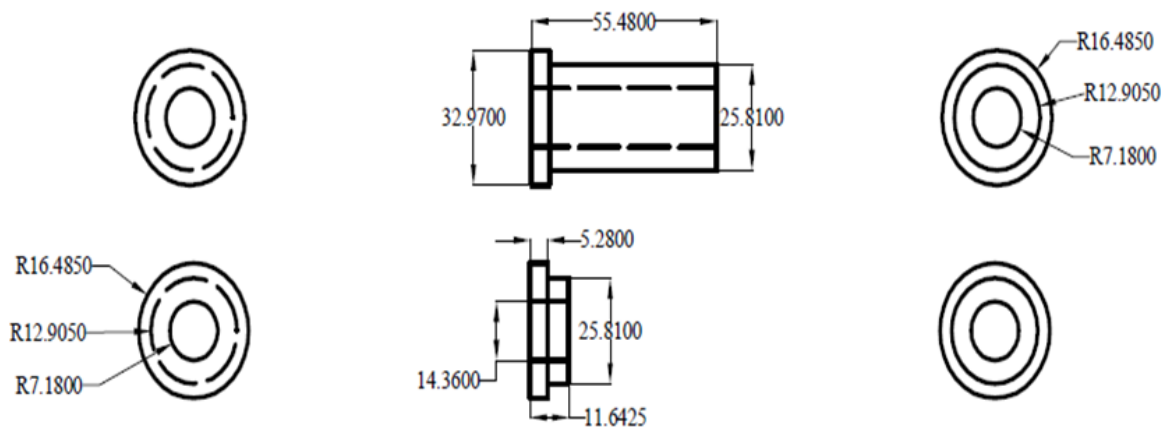

(A)

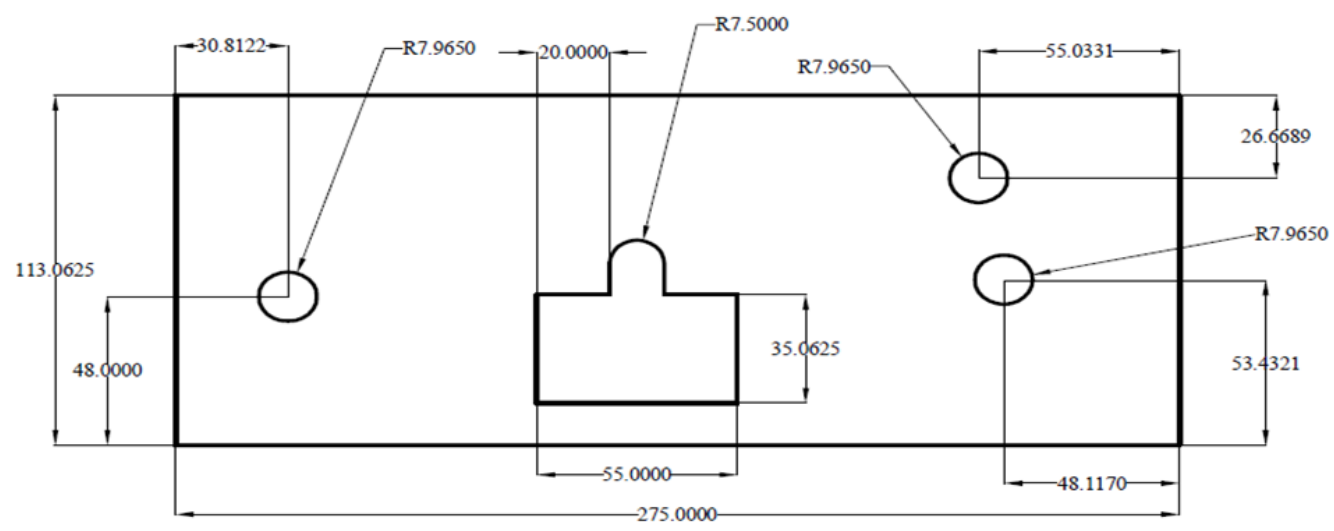

(B)

Fig. 5. Intervention (a) Bush (b) Sheet (all dimensions are in $\mathrm{mm}$ ). 


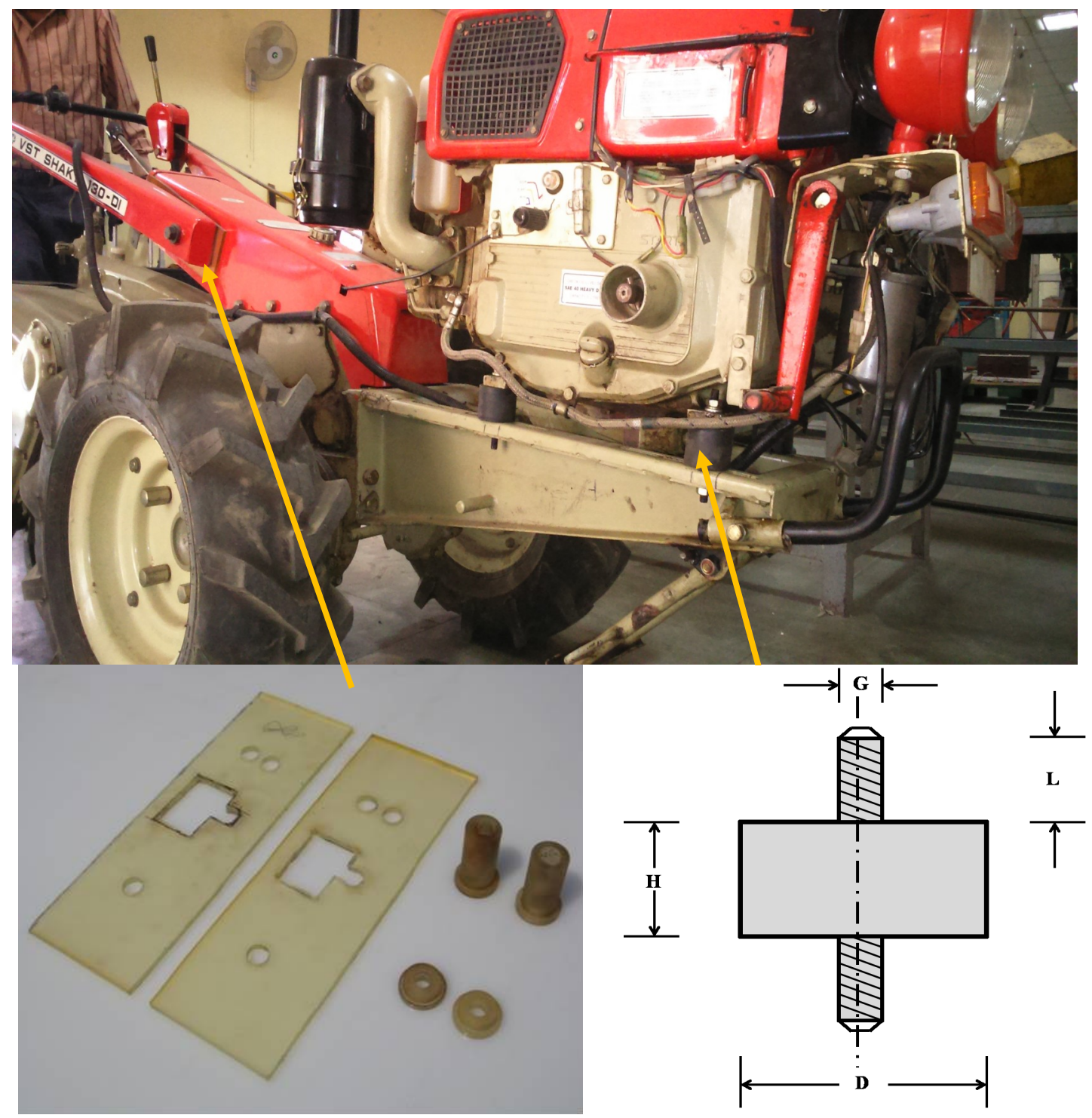

(a)

(b)

Fig. 6. (a) PU Interventions (b) Engine mounts.

$6.15,5.99$ and $6.81 \mathrm{~ms}^{-2}$ respectively in $\mathrm{x}, \mathrm{y}$ and $\mathrm{z}$ direction at $1.0 \mathrm{kmh}^{-1}, 1.33,1.35$ and $1.49 \mathrm{~ms}^{-2}$ respectively in $\mathrm{x}, \mathrm{y}$ and $\mathrm{z}$ at $1.5 \mathrm{kmh}^{-1}$ and $2.23,2.43$ and $2.82 \mathrm{~ms}^{-2}$ respectively in $\mathrm{x}, \mathrm{y}$ and $\mathrm{z}$ at $2.0 \mathrm{kmh}^{-1}$.

Results show that in both the operations the vibration magnitudes in $\mathrm{x}$-direction is higher than the $\mathrm{y}$ and the $\mathrm{z}$ axes. It means the $x$ axis vibration is the major contributor to the vibration total value in each operations. Vibration magnitudes increased with increase in the speeds from 1.0 to $2.0 \mathrm{kmh}^{-1}$. Mehta et al. (1997) reported that the weighted rms acceleration levels in longitudinal and vertical directions were increased with the increase in the forward speeds under all operating conditions (transportation, rotatilling and rotapuddling).

Vibration magnitudes of power tiller with interventions: With interventions of PU and engine mounts the vibration magnitudes in the stationary mode are as shown in the Fig. 9.
It is clear from Fig. that vibration magnitudes increased with increase in speed without interventions. With the interventions as the forward speed increased from 1.0 $\mathrm{kmh}^{-1}$ to $1.5 \mathrm{kmh}^{-1}$ vibration magnitudes were decreased and when the speed increased from $1.5 \mathrm{kmh}^{-1}$ to 2.0 $\mathrm{kmh}^{-1}$ vibration magnitudes were increased for $\mathrm{x}$ and the $\mathrm{z}$ axes. But for $\mathrm{y}$ axis vibration magnitudes were decreased as the speed increased from $1.0 \mathrm{kmh}^{-1}$ to 2.0 $\mathrm{kmh}^{-1}$.

The rms acceleration in transportation mode with the intervention are shown in the Fig. 10.

In transportation mode with intervention the vibration magnitudes decreased for all three axes at 1.0 to 1.5 $\mathrm{kmh}^{-1}$ and as speed increased from 1.5 to $2.0 \mathrm{kmh}^{-1}$, vibration magnitudes increased.

The natural frequency of engine isolators used as interventions was $7 \mathrm{~Hz}$. To attain three different forward speeds the engine rpm were attained by changing the 


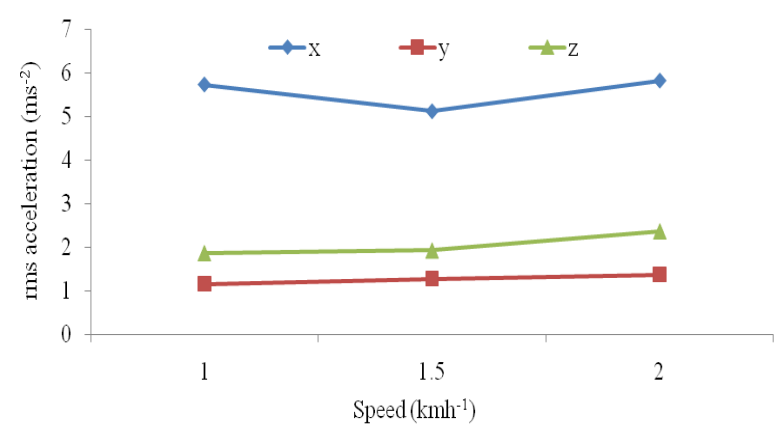

Fig. 7. Vibration magnitudes in stationary mode in different directions.

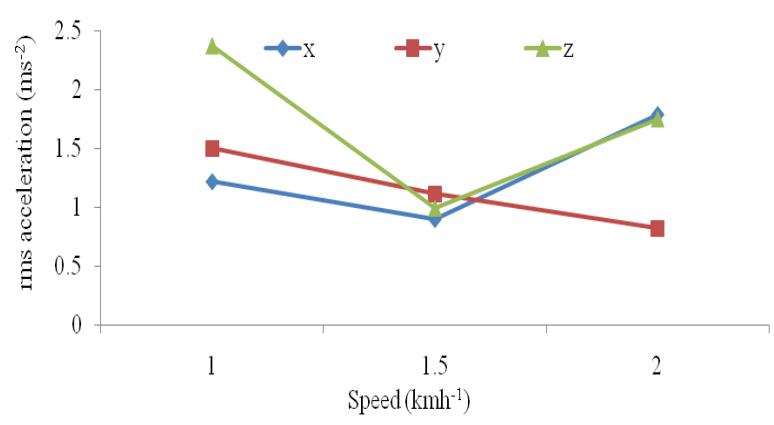

Fig. 9. Vibration magnitudes in stationary mode in different directions

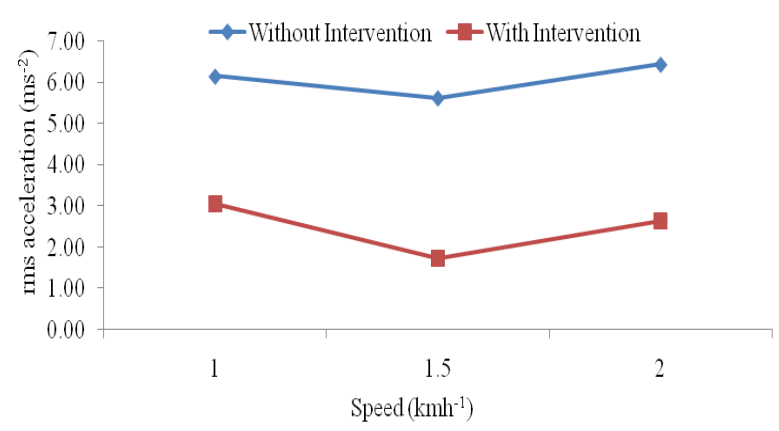

Fig. 11. Vibration total value in stationary mode

$\mathbb{\$}$ Stationary mode

Transpoitation mode

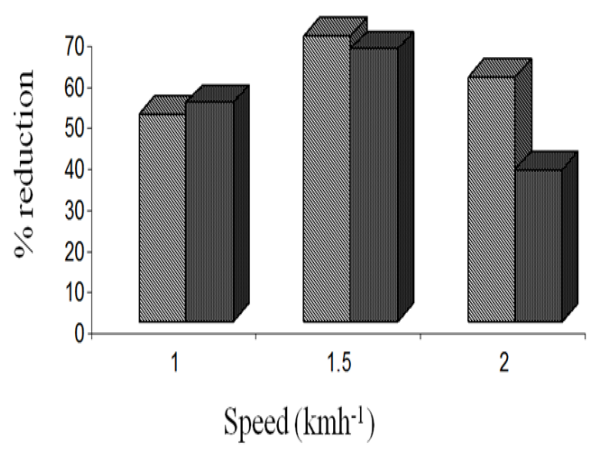

Fig. 13. Percent reduction in vibration total value.

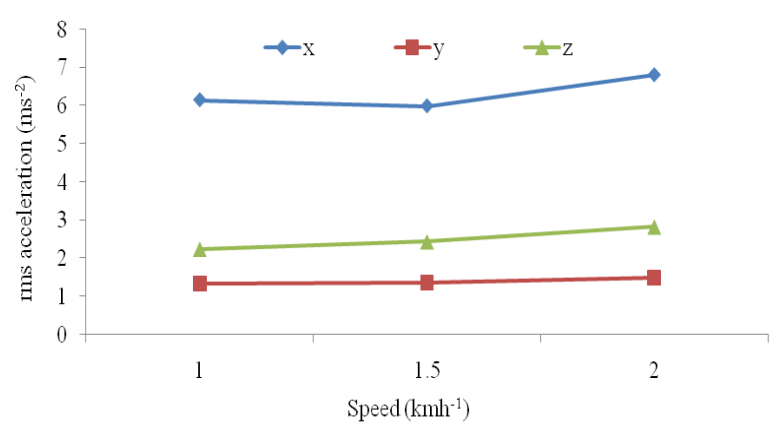

Fig. 8. Vibration magnitudes in transportation mode in different directions.

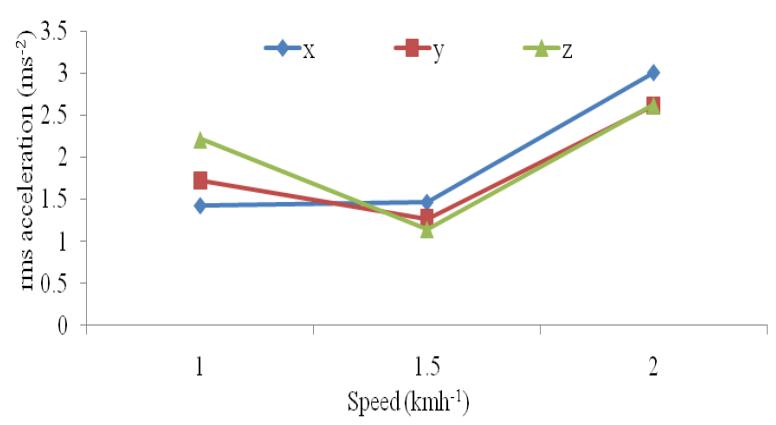

Fig. 10. Vibration magnitudes in transportation mode in different directions

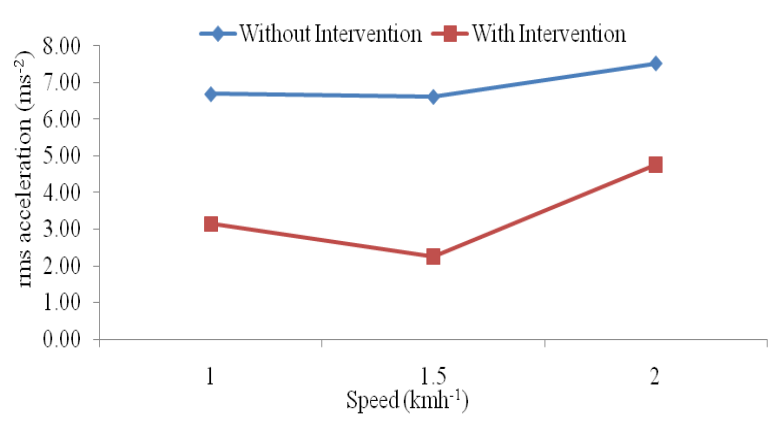

Fig. 12. Vibration total value in transportation mode

accelerator position. The revolutions per second for 1.0 $\mathrm{kmh}^{-1}$ were 8 , for $1.5 \mathrm{kmh}^{-1}$ were 10 and for $2.0 \mathrm{kmh}^{-1}$ were 14. So the power strokes in one second at 1.0, 1.5 and $2.0 \mathrm{kmh}^{-1}$ were 4,5 and 7 respectively. At $1.0 \mathrm{kmh}^{-1}$ the natural frequency of isolators were twice the power strokes. At $1.5 \mathrm{kmh}^{-1}$ the difference between number of power strokes per second and the natural frequency was high so vibration reduction was more than 1.0 and 2.0 $\mathrm{kmh}^{-1}$.

Vibration total value with and without interventions: The vibration magnitudes with intervention and without intervention are shown in the Fig. 11 for stationary operation. Similar trends were achieved for with interventions and without interventions. The vibration total value at handle of the power tiller were $6.15 \mathrm{~ms}^{-2}$ and $3.06 \mathrm{~ms}^{-2}$ at $1.0 \mathrm{kmh}^{-1}, 5.62 \mathrm{~ms}^{-2}$ and $1.74 \mathrm{~ms}^{-2}$ at 1.5 $\mathrm{kmh}^{-1}$ and $6.44 \mathrm{~ms}^{-2}$ and $2.63 \mathrm{~ms}^{-2}$ at $2.0 \mathrm{kmh}^{-1}$ without 
Table 1. Dimensions of engine vibration isolators.

\begin{tabular}{cccccc}
\hline $\mathbf{D}$ & $\mathbf{H}$ & $\mathbf{G}$ & $\mathbf{L}$ & Load & Natural Frequency Hz \\
$\mathbf{M m}$ & $\mathbf{M m}$ & Thread & $\mathbf{m m}$ & 75 & 7 \\
\hline 60 & 45 & Mा0 & 30 & 75 & 7 \\
\hline
\end{tabular}

intervention and with intervention respectively.

With the interventions the total vibration values for transportation at different selected speeds are shown in the Fig,12. The vibration total value for transportation mode with intervention were 6.68 and $3.14 \mathrm{~ms}^{-2}, 6.60$ and 2,25 $\mathrm{ms}^{-2}$ and 7.52 and $4.76 \mathrm{~ms}^{-2}$ with intervention and without intervention at $1.0,1.5$ and $2.0 \mathrm{kmh}^{-1}$, respectively. With the application of the interventions vibration reduction was 50.24, 69.06 and $59.08 \%$ (Fig.13) at 1.0, 1.5 and $2.0 \mathrm{kmh}^{-1}$ in the stationary mode. In the transportation vibration reduction were 52.96, 65.98 and $36.67 \%$ at $1.0,1.5$ and $2.0 \mathrm{kmh}^{-1}$, respectively. Binisam and Kathirvel (2009) also reported that 50 to $60 \%$ vibration reduction were achieved by installing the vibration isolators at engine, handle bar and the handle. Engine mounts were retrofitted for the interface between engine and the chassis. Due to complex design and properties of the material different percentage of vibration reductions were achieved at different axes and speeds.

The vibration reduction were high in stationary mode than transportation mode because in the stationary mode vibration were coming only from the engine but in transportation mode the surface profile also contributes to vibration. So the situation in the transportation mode was more complex than the stationary operation of the power tiller for vibration at the handle.

\section{Conclusion}

In the present study the vibrations were measured at two different operations of the power tiller. In power tiller the major contributor to the hand arm vibration is the single cylinder engine. So engine mounts were retrofitted to reduce the engine vibrations. The vibration transmission was further reduced from the sheet and bush type interventions between chassis and the handle bar of the power tiller. The design and the installation of suggested interventions are easy and adaptive for both existing and the new machines. With the incorporation of the interventions at respective interfaces vibration reduction of up to $70 \%$ can be achieved in both the selected operations.

\section{REFERENCES}

Anonymous, (2013). State of Indian Agriculture 2012-13. Directorate of Economics and Statistics, Department of Agri- culture and Corporation, Ministry of Agriculture, New Delhi http://164.100.47.132/paperlaidfiles/ AGRICULTURE/State\%20of\% 20Indian \% 20Agriculture \%202012-13\%20(English) \%20with\%20cover.pdf, $221 \mathrm{p}$.

Binisam and Kathirvel, K. (2006). Vibration characteristics of walking and riding type power tillers. Biosystems Engineering. 95 (4) : 517-528.

Binisam and Kathirvel, K. (2009). Development and evaluation of vibration isolators for reducing hand transmitted vibration of walking and riding type power tillers. Biosystems Engineering. 103 : 427-437.

Chaturvedi, V., Kumar, A., Singh, J.K. (2012). Power tiller: Vibration magnitudes and intervention development for vibration reduction. Applied Ergonomics. 43 : 891-901.

Dewangan, K.N. and Tewari, V.K. (2010). Handle grips for reducing hand-transmitted vibration in hand tractors. International Agricultural Engineering Journal. 19 (2) : 4857.

Griffin, M.J. (1996). Handbook of Human Vibration. Acadmic press, London.

IEC 61260. (1995). Electroacoustics - Octave-band and fractional-octave-band filters. Geneva, Switzerland.

IEC 61672-1. (2002). Electroacoustics - Sound Level Meters Part 1: Specifications. Geneva, Switzerland.

ISO 2631-1. (1985). Evaluation of human exposure to whole body vibration - Part:1. General Requirements, Geneva, Switzerland.

ISO 5349. (2001). Mechanical vibration-Guidelines for the measurement and the assessment of human exposure to hand transmitted vibration. Geneva, Switzerland.

Mehta, C.R., Tiwari, P.S., Varshney, A.C. (1997). Ride vibrations on a $7.5 \mathrm{~kW}$ rotary power tiller. Journal of Agric. Engng Res. 66 : 169-176.

Mehta, C.R., Chandel, N.S., Senthilkumar, T., Singh, K.K. (2014). Trends of Agricultural Mechanization in India. CSAM Policy Brief (Issue 2).

Ragni, L. (1993). Vibration transmitted to the hand-arm system by walking tractors. Third part: a solution for vibration reduction. Rivista di Ingegneria Agraria. 24 (4) : 193-198.

Rao, S.S. (2000). Mechanical Vibrations. Addison-Wesley Publishing company, Boston.

Tewari, P.K., Dewangan, K.N., Karmakar, S. (2004). Operator's fatigue in field operations of hand tractors. Biosystems Engineering. 89 (1) : 1-11.

Ying,Y., Zhang, L., Xu, F. and Dong, M. (1998). Vibratory characteristics and hand-transmitted vibration reduction of walking tractor. Transactions of the ASAE. 41 (4) : 917922. 